\title{
Identity and self-esteem in the context of music and music therapy: a review
}

Participation in music therapy offers opportunities for the participants to engage in identity work - to define, develop, or reflect on their understanding of themselves, and to cultivate new expressions of self-identity. The music therapy involves breaking away from the reality and engaging in intense interactions, which in turn facilitate relationships between participants. Patients tend to be more open to new kinds of experiences and explore new ways of perceiving themselves and others. Their self-understanding develops and leads to self-acceptance and personal growth. Although questions concerning the relationship between music therapy and human identity have been asked since antiquity, many issues have still not been resolved. As of today, there are no publications that systematically review the current state of knowledge.

This article aims to review the available empirical evidence in order to identify the relationship between music therapy processes, identity, and specific individual identity variables, such as self-esteem. Also, it attempts to discover how self-regulatory behavior relates to both general music instruction and interventions designed to enhance self-esteem and identity.

We searched PubMed and Psyclnfo up to 13.09.2016. Screening, eligibility, and data extraction were done by one reviewer. Out of 31 relevant records, 20 were assessed for eligibility, and 14 were included. There was marked variation across included studies regarding type of MT approach used, type of participants, settings, outcomes and measurement tools. A qualitative analysis showed that expression of emotion and a sense of agency (which is considered valuable for both the client and those around them) is a way to provide one's damaged Self with healthful aspects of personality, thus improving one's self-esteem.

This review provides insight into the effects of music therapy processes, specifically self-knowledge (music identity) and self-esteem determined by the psychological processes entailed in some kinds of music activities.

\section{KEY WORDS}

identity; self-esteem; music; music therapy

ORGANIZATION - 1: Institute of Psychology, University of Gdansk, Gdansk, Poland · 2: GAMUT, Uni Health Research, Bergen, Norway

AUthors' Contributions - A: Study design - B: Data collection - C: Statistical analysis - D: Data interpretation .

E: Manuscript preparation · F: Literature search $\cdot$ G: Funds collection

CORRESPONDING AUthor - Rafał Lawendowski, Ph.D., Institute of Psychology, University of Gdansk, 4 Bażyńskiego Str., 80-309 Gdansk, Poland, e-mail: psyrl@ug.edu.pl

TO CITE THIS ARTICLE - Lawendowski, R., \& Bieleninik, Ł. (2017). Identity and self-esteem in music and music therapy

context: a review. Health Psychology Report, 5(2), 85-99. doi: https://doi.org/10.5114/hpr.2017.64785

RECEIVED 30.10.2016 · REVIEWED 12.11.2016 · ACCEPTED 24.11.2016 · PUBLISHED 04.01.2017 


\section{BACKGROUND}

For centuries, many theorists and researchers have been exploring the healing powers of music. Be it the Bhagavad Gita (the holy Hindu scripture), or the hieroglyphs of ancient Mayans or Egyptians, through the ages numerous sources have attributed enchanting, magical, or healing properties to music. The idea of music having purifying, harmonizing, and medicinal effects on the human soul is rooted in the

Rafat ancient literate societies. Pythagoras claimed that Lawendowski, Łucja Bieleninik perfect ratios in music mirror the divine harmony of the cosmos. Viewed from this perspective, catharsis uses the right melodies to harmonize and improve the soul by changing its state to the opposite one. On the other hand, the Aristotelian concept of catharsis is derived from the idea of mimesis in which music imitates mental states - and more precisely, the flaw it is supposed to eradicate. In order to free oneself from a given emotion, we should intensify it with music, thus leading to making right what was wrong (Fubini, 1991). With this in mind, it is hard to consider being in contact with music as developing only one's musical skills. On the contrary, coming into contact with music paves the way for a change - psychological development - in different areas of one's psychological functioning (Hargreaves, 1986).

Music has many functions, roles, and psychological applications which have been broadly described in the literature (cf. Schäfer, Sedlmeier, Städtler, \& Huron, 2013); apart from that, it is of special use as a therapeutic and helping tool. Professional music therapy (MT) formally began during World War II, when it served as a kind of musical anesthesia during surgery and a psychiatric method for treating war veterans (Rorke, 1996). It developed over the following next years; for example, MT was no longer treated as a mere substitute for pharmacological treatment. Not only the medical perspective is emphasized, but also the psychological, individual aspects of communing with music, other people, and oneself (Galińska, 2005), since music resonates not only with physiological and emotional processes, but also with one's personality and cognition. Thanks to properly planned music-based interventions one can develop one's intellectual abilities, as well as one's personal identity as a result of abandoning negative self-images, and even improve one's self-esteem (MacDonald \& Miell, 2002). As we point to the relation between music and a person's deeply individual dimensions, it is worth noting that the two factors do not appear "side by side", but are rather in mutual interaction, cooperating in a way. On the one hand, music provokes specific inner states, while on the other one's inner self can be expressed through music of a certain character (Kopacz, 2005; Lawendowski, 2009). Relations between how music and the psyche are organized are interesting and significant enough (from both the cognitive and clinical points of view) that they have become a theoretical basis for clinical tools such as the Music Preference Test of Personality (Cattell \& Anderson, 1953). Moreover, the fact that the relationship exists points to a much broader mechanism of the isomorphism of musical and psychological phenomena, i.e., to their structural and functional resemblance.

\section{MUSIC AND SELF-REFERENCE}

Music can be defined as sounds that are produced by people and evoke pleasant auditory sensations (Cook, 2000). Music is created by human thought and activity. It appears to be a part of nature and exists independently of humans, but at the same time it is imbued with human values. People can think through music; they can use it to express themselves and explore their identities. A few seconds is enough for listeners to determine the genre and whether they like it, whether it suits them. In today's world, as individuals choose a kind of music, they decide for themselves not only who they want to be but also what they truly are - and then they send this message to others.

During listening to music, the self-reference is a basic human reaction (Sloboda, 2005). Listening to music, although personal and individualized, is a person's primeval drive, observed already in small children, individuals with no music education, and in almost every culture around the globe. Active listening to music plays a significant role in exploring and integrating one's identity (Larson, 1995). Moreover, music is a form of expression - people use it both to express themselves and to gain knowledge about others. This comes as no surprise when we consider research findings on people who use music, both consciously and unconsciously, to demonstrate certain attitudes, values, and beliefs (Lull, 1987; Larson, 1995; North \& Hargreaves, 1999). Unsurprisingly, then, drawing on what is discussed above, music psychology developed a notion of identity, musical identity in this case, which refers to the Self that creates and listens (Hargreaves, Miell, \& MacDonald, 2002). The term "musical identity" contains a description of interrelations between one's self-image and music. It can be defined by specific behaviors as attending concerts or listening to specific albums. Musical identity has not only an individual aspect (it helps to understand oneself), but also a social aspect (when it is outwardly demonstrated for others to see). People use music to manifest their identities, just as they do with language and speech (Hargreaves, Miell, \& MacDonald, 2002). Researchers further diversify the notion of musical identity by introducing terms such as "identities in music", which came to encom- 
pass all recognizable social and cultural musical roles (conductor, composer, instrumentalist, vocalist, and so on). On the other hand, the term "music in identities" has been studied as well. This approach implies that music is of no small importance in shaping one's non-musical identity - music contributes to emphasizing one's roles based on sex, social origin, and nationality. Researchers who investigate this issue analyze the ways in which music and musical activities prompt, guide, or result from the processes of experiencing oneself among others. To sum up, in the scope of musical identity music is understood as a way of expressing one's self-image. Musical identity is a crucial factor determining the degree to which an individual can establish contact with music. It is therefore important to consider it as a multidimensional issue targeted at many aspects of an individual's contact with music.

To summarize, one's identity is a subsystem of self-knowledge, i.e., a part of the self as object. On the other hand, as a mental existence it is an integral part of the self as subject. Finally, assessing one's self is called self-esteem. Psychological identity is concerned with the "Who am I?" kind of problems, and self-esteem is evaluating one's features on the positive-negative continuum (Greenberg, 1970). Keeping positive self-esteem is supposed to help to maintain positive emotions which motivate people to act and shield them against anxiety (Pyszczynski, Greenberg, \& Solomon, 1999). In order to have the energy to act, instead of falling into torpidity and powerlessness (e.g., when in depression), high and positive self-esteem is essential (Kuhl, 2000).

MacDonald and Miell (2002) demonstrated that educational programs in music composition and learning to play an instrument can contribute to developing one's identity, but also increase one's self-esteem in children with learning disabilities and developmental disorders. It should be noted that such children struggle with more than just the difficulties of intellectual or motor character; they are also physically different from their peers and are often shunned by those around them. Public performances draw the audience's attention to these persons' "healthy" aspects - which could have gone unnoticed for a long time if a person had been assigned a disability label. What is more, engaging in creative work as a rightful member of a music band can result in how a disabled person sees oneself, which then translates into better self-esteem and, consequently, into better relations with others.

Given the recent expansion of research in the area of MT, the literature on relationships between (musical) identity, one's directly related self-esteem, and the MT process mentions it ambiguously, too often leaves it unexplored, or treats it as anecdotal (cf. Aldridge, Schmid, Kaeder, Schmidt, \& Ostermann, 2005). The motivation to conduct the current systematic review was to provide a qualitative analysis of identity and self-esteem in the MT context. We aimed to report the available empirical evidence on the relationship between MT processes, identity, and specific individual identity variables, such as self-esteem.

\section{METHODS}

One reviewer searched electronic databases (PubMed and PsycInfo) for eligible studies by using the following terms: (music therap* AND identity) OR (music therap* AND self-esteem). We accepted journal articles published in English or Polish. The year of publication did not limit the search. Unpublished studies were not included. All potentially relevant records were extracted to EndNote reference management software. At this stage, duplicates were detected and deleted. One reviewer inspected titles and abstracts to exclude irrelevant reports and assessed full texts to determine eligible studies. All uncertain cases were discussed with a second reviewer. We included participants of both genders, of non-specific ethnicity, in all ages. We accepted all forms of MT and music-based studies compared with standard care (SC) or SC combined with other treatment. This review includes prospective studies of intervention effects (i.e., randomized, non-randomized controlled, or without a control group), case studies and theoretical publication. We extracted the following information from included papers: study characteristics (year, country, and design), characteristics of the study population (number of participants, diagnosis, age, and gender), description of the intervention (treatment, total number of session and duration), control group (if relevant), outcome(s), measurement tool(s), and results. A qualitative analysis was undertaken due to clinical heterogeneity in study populations, interventions, and the outcomes.

\section{RESULTS}

\section{SEARCH CHARACTERISTICS}

We identified a total of 31 records from the database search. The last search took place on September 13, 2016. After excluding duplicates and clearly irrelevant references, we obtained 20 to assess papers for eligibility. Two publications referring to the same study were merged into one. Of these, 14 met the inclusion criteria and were included in the systematic review.

\section{STUDY CHARACTERISTICS}

The included studies were conducted in a variety of countries worldwide: Australia, China, Germany,
Identity and self-esteem in the context of music and music therapy 
India, Netherlands, Taiwan, UK, and USA. The final sample included 9 studies of intervention effects (Aldridge et al., 2005; Chen, Hannibal, \& Gold, 2016; Clendenon-Wallen, 1991; Grocke et al., 2014; Haines, 1989; Hanser \& Thompson, 1994; Henderson, 1983; Sharma \& Jagdev, 2012; Wu, 2002), 1 case study (Smeijsters \& van den Hurk, 1999), 2 exploratory studies (Daykin, McClean, \& Bunt, 2007; Pavlicevic, O'Neil, Powell, Jones, \& Sampathianaki, 2014) and 2 theoretical articles (Amir, 2012; Gleadhill \& Ferris, Rafat 2010). Sample sizes ranged from 1 (Smeijsters \& van Lawendowski, Łucja Bieleninik den Hurk, 1999) to 200 (Chen et al., 2016). Table 1 presents study characteristics of 9 papers presenting intervention effects.

\section{PARTICIPANT CHARACTERISTICS}

The current review reflects a high level of clinical heterogeneity in regard to the target population (Table 1). We included types of participants with the following problems/diagnosis: adjustment reaction (Henderson, 1983), lacking crucial self-esteem and self-concept (Haines, 1989), severe learning disabilities (Pavlicevic et al., 2014), problems due to fear, depression, and low self-esteem (Wu, 2002), low self-esteem and high academic stress (Sharma \& Jagdev, 2012), adolescents who had been sexually abused in the past (Clendenon-Wallen, 1991), prisoners (Chen et al., 2016), severe mental illness (Grocke et al., 2014), depression of various degrees of severity and schizophrenia (Hanser \& Thompson, 1994), an adult woman who had problems in finding her personal identity and suffered badly from grief, low self-esteem, and feelings of depression (Smeijsters \& van den Hurk, 1999), patients diagnosed with cancer (Daykin et al., 2007), multiple sclerosis (Aldridge et al., 2005), and dissociative identity disorder (Gleadhill \& Ferris, 2010). In summary, 5 trials included children up to 18 years old, and 6 concerned adults. Two theoretical articles did not specify the age of the targeted population. Studies were conducted in hospitals, communities, and prison or home settings.

\section{INTERVENTION CHARACTERISTICS}

There was marked variation across the studies regarding the types of MT approaches used, frequencies and durations. Participants received individual or group therapy. Table 1 presents intervention characteristics.

\section{OUTCOME CHARACTERISTICS}

The current review reflects a high level of clinical heterogeneity, which may be expected given the broad range of outcomes that may be addressed with MT. Self-esteem was evaluated by using the Rosenberg Self-Esteem Scale (SES), Self-Esteem Inventory (SEI), Texas Social Behavior Inventory (TSBI), Rosenberg Self-Esteem Inventory (RSI), Coopersmith Self-Esteem Inventory (CSEI), or Self-Esteem and Self-Acceptance Scale (SESA). Table 1 provides an overview of all outcome characteristics and measurement tools.

\section{QUALITATIVE SYNTHESIS OF INDIVIDUAL STUDIES}

\section{Studies of intervention effects}

Aldridge et al. (2005) included 20 multiple sclerosis (MS) patients (aged 29-47) with episodic, secondary chronic and primary chronic progression and average disease duration of 11 years. Half of the participants were allocated to the group music therapy in Nordoff Robbins' approach, and the second half to the matched control group. The intervention group received three blocks of music therapy in single sessions during one year (a total of 8-10 sessions). The results showed that MT helps to (a) improve one's communication skills, and consequently (b) boosts one's self, experiencing of which could be distorted as a result of the disease. While there was no improvement in cognitive and functional parameters, researchers observed changes (measured with the effect size when comparing two groups of participants) in self-acceptance. The participants (as it turned out - to their own surprise) found within themselves previously unexplored areas of creativity and musical skills. Moreover, 7 patients declared an increase in self-confidence to be a result of the therapy. The researchers noticed that prolonged illness (and a related process of social stigmatization) may lead to spoiled identity. Therefore, any therapeutic attempt to enhance a patient's mood and self-esteem is important to alleviate the social stigma and difficulties in understanding oneself. The authors suggested that we may have to look at MS not only as a neurodegenerative disease, but also a dialog-degenerative disease where the communications factor has been disrupted. The proposed form of treatment proved to be an effective method to express oneself; and we should not forget that individuals with multiple sclerosis have a complex structure of needs which go beyond those directly related to, for example, improving their motor abilities. The patients perceived music and the process of MT as "something moving", and this experience was due to pushing negative, disease-related thoughts away, being able to express oneself, to feel freedom, pleasure, and security. Music can be seen as a therapeutic tool for changes viewed from the aesthetic standpoint. From this perspective, patients try to grasp and understand the nature and value of a musical piece, and the aesthetic structure is built 


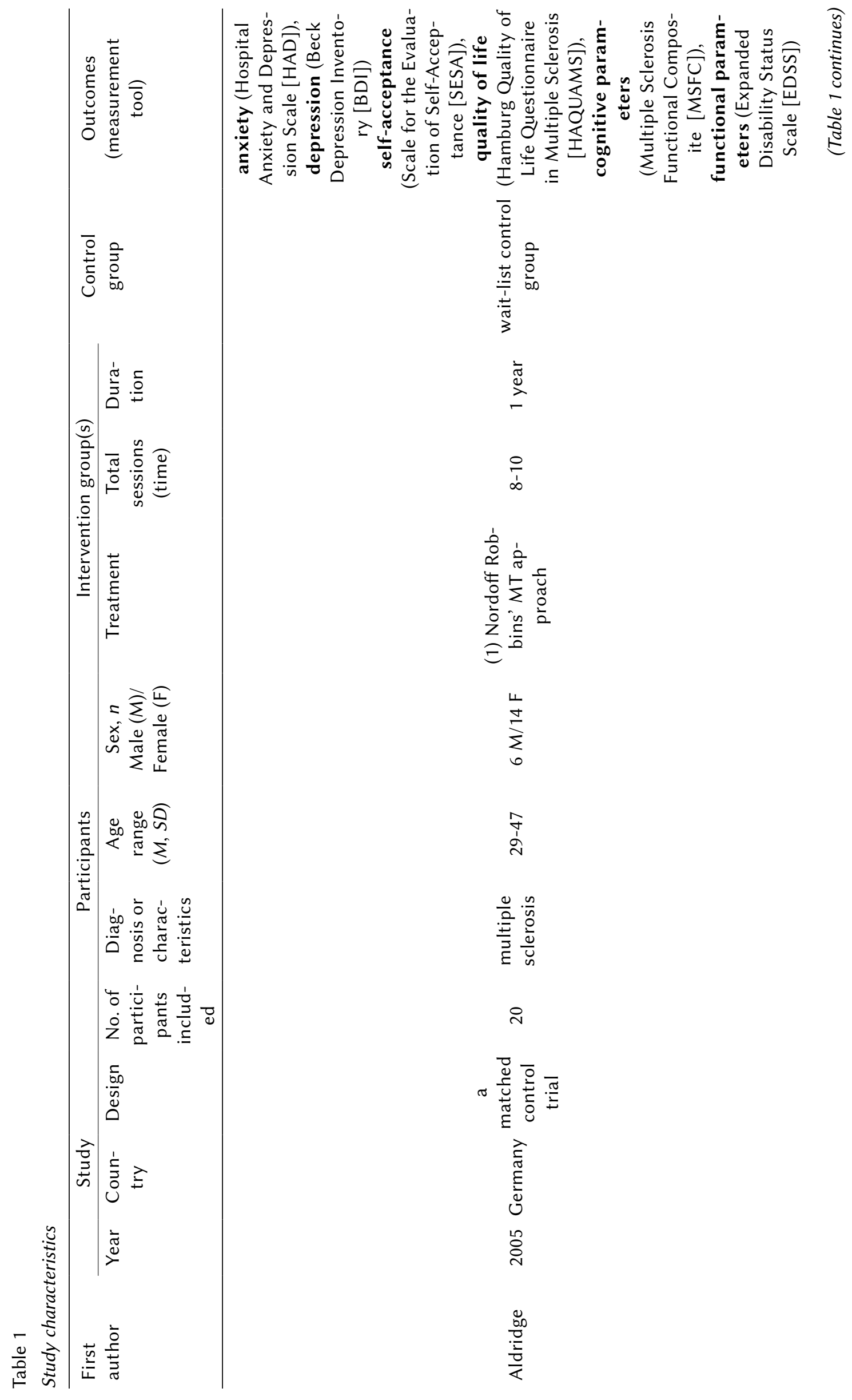

Identity and self-esteem in the context of music and music therapy 


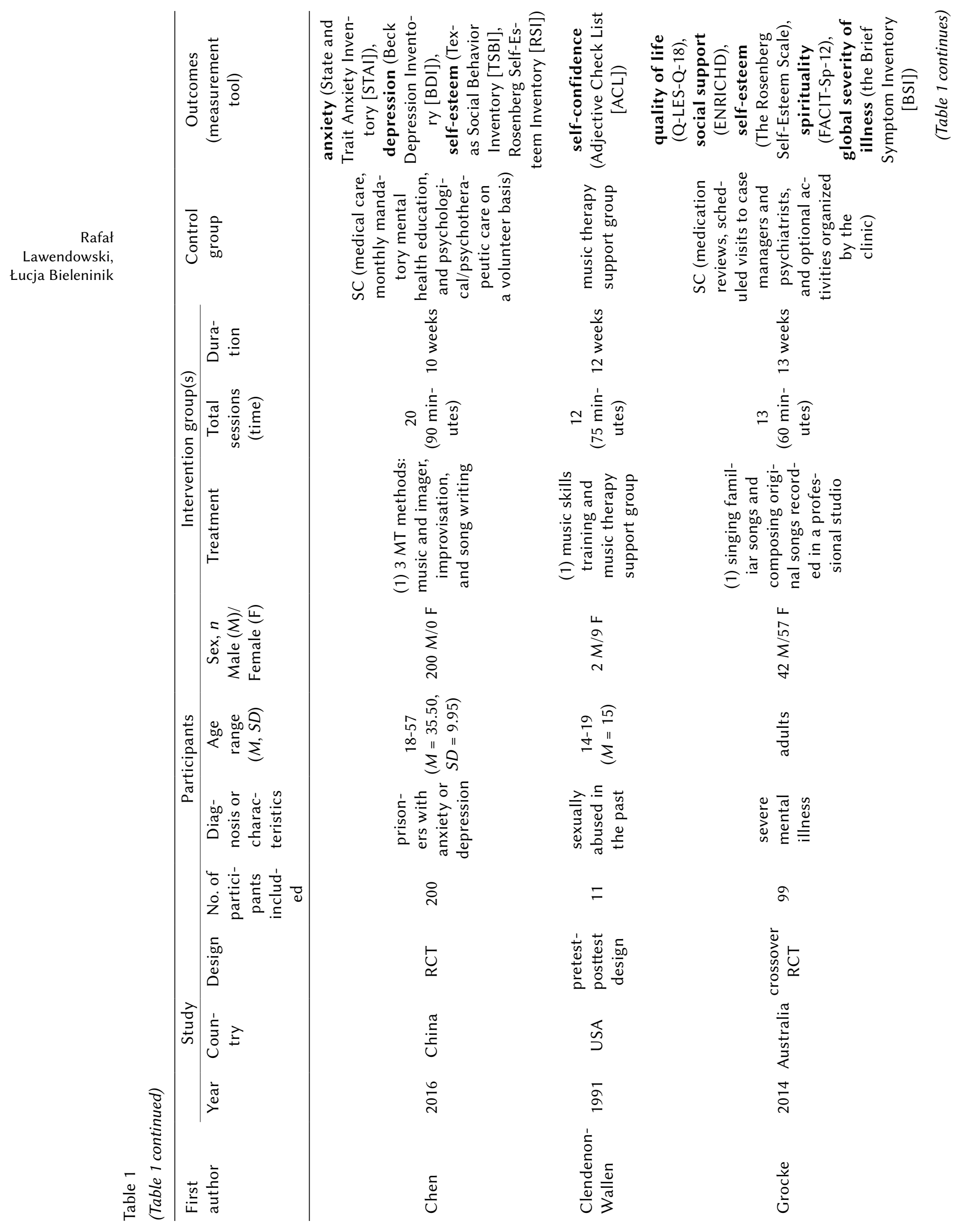




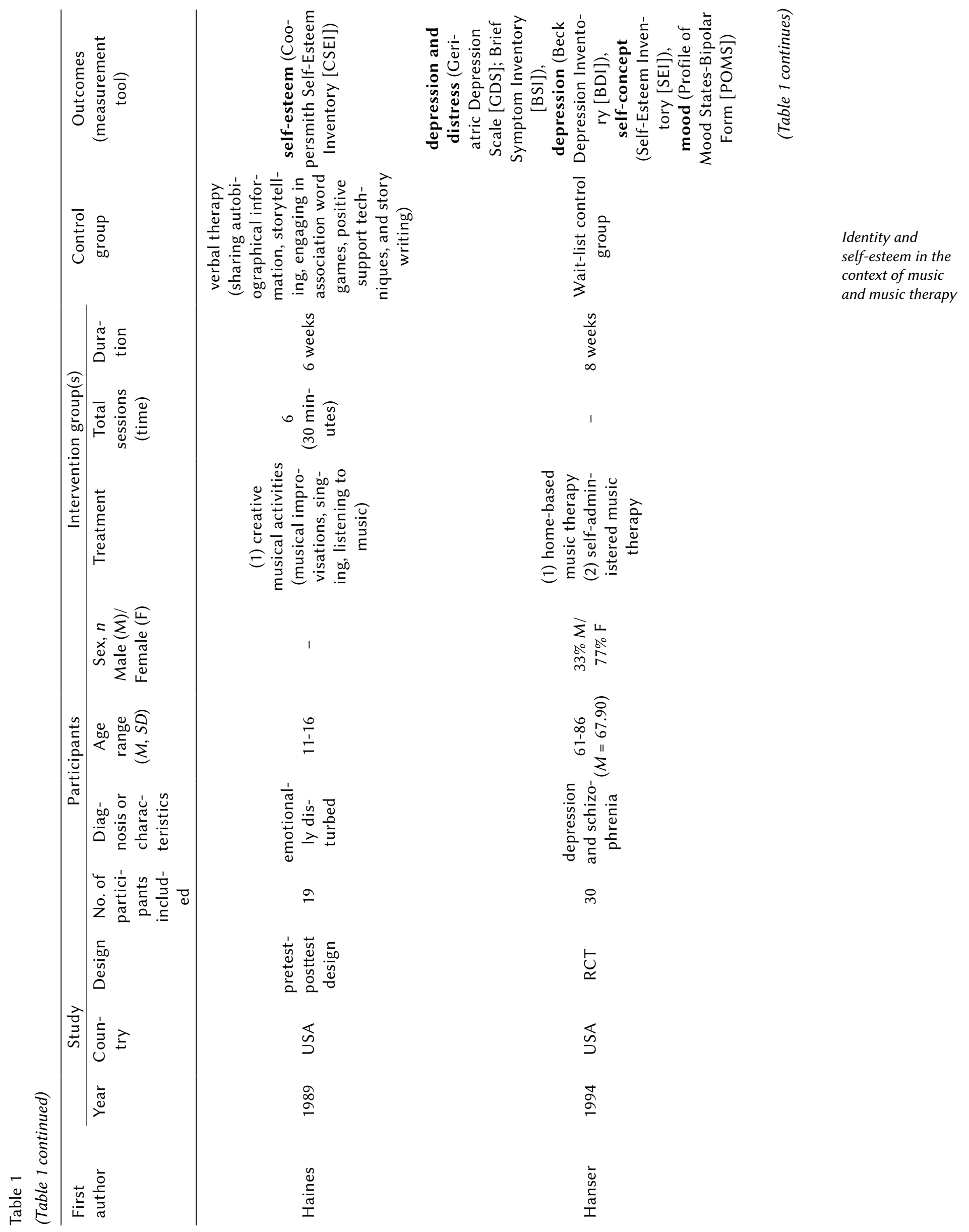




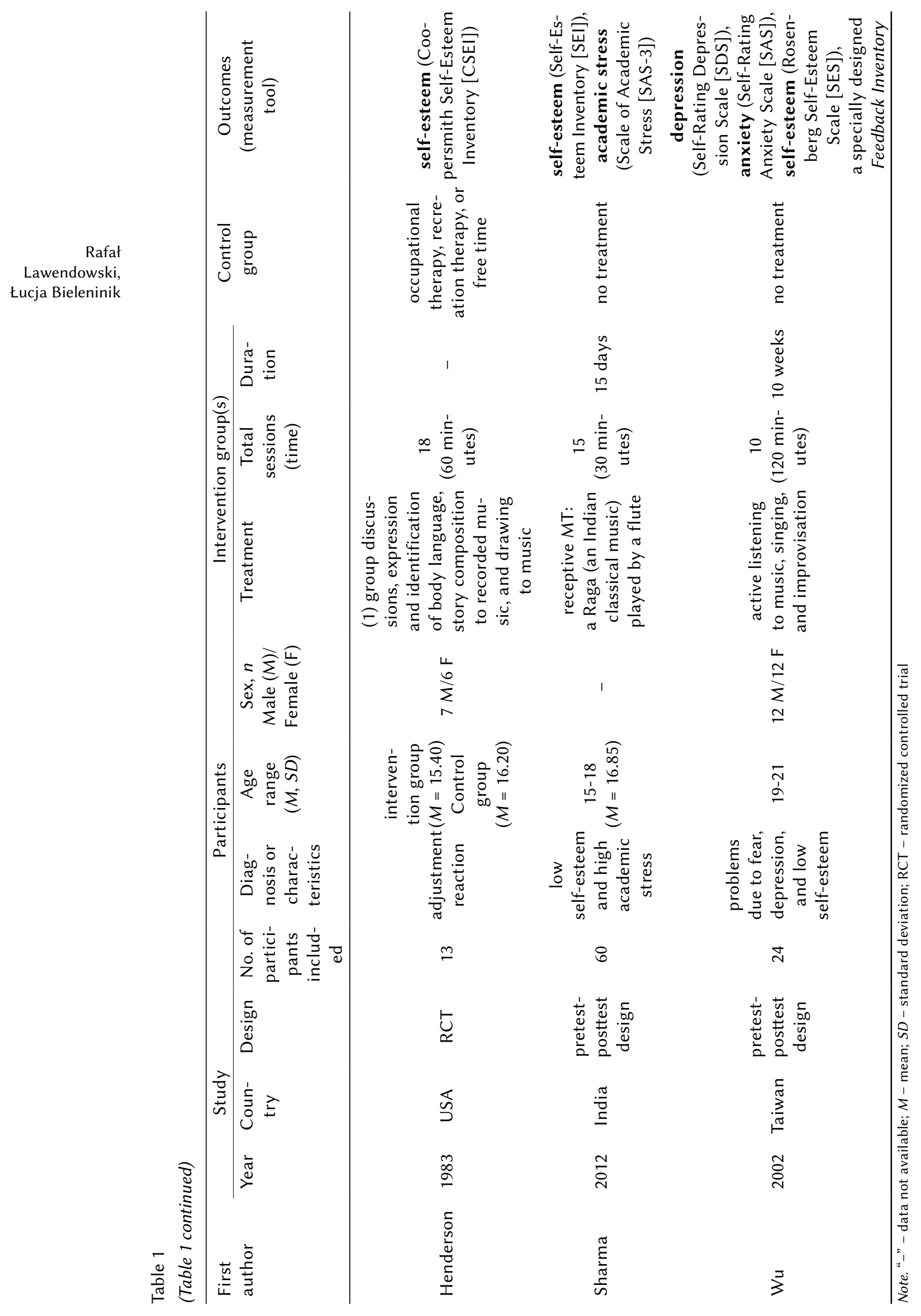


on top of these two. This approach not only makes the entire healing process more flexible, but also develops aesthetic feelings, which patients might have been unable to experience on a daily basis.

The issue of social consequences of working with musical identity can be found in a study by Chen et al. (2016). In this randomized controlled trial, 200 Chinese prisoners with anxiety or depression (all of them males from one prison) were allocated to MT or SC. In the first three sessions the following MT methods were used: music and imagery, improvisation, and songwriting. In the following stages of the program, the session leader together with the participants chose one of these aforementioned methods, and the session itself was preceded by discussing the participants' emotions, thoughts, and personal problems. The analysis revealed that MT was more effective in mitigating fear, reducing symptoms of depression, and boosting self-esteem than standard treatment. The result regarding self-esteem was explained by the fact that it becomes more stable later in one's life. Considering the methods used and results obtained, the researchers postulated to extend our understanding of self-esteem, traditionally treated as a global dimension (i.e., global self-esteem). The obtained data confirmed the impact of MT on one's self-esteem manifested in social behaviors. Also, what was especially important, this effect was more pronounced among younger and/or less-educated inmates.

Clendenon-Wallen (1991) treats MT as one of the elements of treatment programs for sexually abused adolescents, who often suffer from a low sense of self-worth. This study included 11 adolescents who had been sexually abused in the past in order to increase self-worth by using MT. The author suggested that these teenagers are not able to express their feelings directly, nor can they resolve problems through direct dialog. It was hypothesized that a greater psychological comfort (greater self-confidence) will result from musical expression. A music group included song or "rap" writing, rhythm playing, song discussion, or improvisation, lyrics analysis, and/or creative movement. In addition, the adolescents participated in designing record album covers. The proposed music-based activities (making music and gaining music skills in the process) turned out to positively correlate with increasing the participants' sense of self-worth and self-confidence. The author suggested that nonverbal aspects of music made it an excellent way of communication, facilitating expression through alternative mediums. Not only did music ease the adolescents' anxiety reactions; it was also useful in the process of socialization and verbalization and served as a starting point for discussing personal matters. Group improvisation turned out to enhance group cohesion and cooperation between those involved in treatment. Music in and of itself is an important part of youth cultures and has an important psychological role to play in their lives.

Grocke et al. (2014) determined whether group therapy had a positive impact on quality of life, social enrichment, self-esteem, spirituality, and psychiatric symptoms of participants with severe mental illness, and how they experienced the intervention. The authors included 99 individuals who were randomized to either weekly group MT followed by SC or SC followed by group MT. Crossover took place after 13 weeks. The intervention comprised singing familiar songs and composing original songs recorded in a professional studio. This randomized crossover design used an embedded-experimental mixed methods strategy, in which qualitative data (focus group interviews and lyrics analysis) were collected following the intervention and analyzed after the quantitative analysis. Measures were conducted at baseline, 13, 26 and 39 weeks. The results showed that group MT improved the quality of life and self-esteem (based on the intention-to-treat analysis). Per-protocol analysis suggested greater benefit for those receiving more sessions. Participants were predominantly musically naive, and engagement in the group MT provided them with an opportunity to find a creative aspect of their personality. Moreover, group singing and songwriting was a creative option for social connections. The authors suggested that MT should be considered as a component of holistic care for individuals with severe mental illness.

We further analyzed this concept based on the findings that MT programs which improve self-esteem, emphasize mood recognition, mood awareness, and group cohesion can be effective when working with emotionally disturbed adolescents. Haines (1989) decided to test this claim in practice, assuming that improved self-esteem is the major goal in therapy of those individuals who typically lack crucial self-esteem and self-concept. The author emphasized that there is a shortage of scientific research and clinical reports dealing with the music-self-esteem relationship, comparing MT with verbal therapies. Nineteen adolescents with the psychological problems mentioned above participated in the study. The eligibility criteria were as follows: lack of academic and social development apparently not caused by intellectual, sensory, or physical impairments; lack of satisfactory interpersonal relationships with peers and adults; frequent occurrence of inappropriate and inconsistent behavior; frequent moods of depression and unhappiness. The intervention group included 10 participants who took part in 6 weeks' long MT focused on creative musical activities (musical improvisations, singing, listening to music). In the control group, 9 participants received traditional, 6 weeks' long verbal therapy (sharing autobiographical information, storytelling, engaging in associa-
Identity and self-esteem in the context of music and music therapy 
tion word games, positive support techniques, and story writing). The results showed no intergroup differences in quantitatively measured self-esteem. Haines suggested that this could be explained by such factors as a small number of individuals in both groups, no control over other life experiences of the participants, or numerous breaks in therapy sessions. The expected differences became indirectly apparent after analyzing the thoughts described in the daily notes. The analysis revealed that all participants from the MT group were highly satisfied and motivated to act (as opposed to the control group, where participants avoided activity and often had to be persuaded to actually do anything). Haines is of an opinion that a clear indicator of differences between the effectiveness of the two therapies is to be found in a statement by one the MT session attendees: "I thought this was this supposed to be therapy or something... Well, we did get our feelings out, and it sure felt good to come in and play the drums when I was angry" (Haines, 1989, p. 88). As for the individuals from the control group, they completed little tasks intended to improve their self-esteem.

One example of research on the effectiveness of MT among the elderly is a study by Hanser and Thompson (1994). The authors aimed to evaluate the effects of listening to music on different ways of reducing anxiety and stress, and of improving mood and self-esteem. Thirty persons (aged 61-86) with depression of various degrees of severity and schizophrenia were randomly allocated to one of three groups: (1) home-based music listening provided by a music therapist; (2) self-administered music listening with moderate therapist intervention; or (3) a wait-list control group. It was hypothesized that the two music-involving conditions would result in superior improvement of psychological measures (as compared with the control group). Home-based MT and self-administered MT yielded similar, significantly better compared to the wait-list control group results in depression, distress, self-esteem, and mood. Moreover, these improvements were maintained over a 9-month follow-up period. This article offers an interesting contribution of the use of MT with older adults experiencing symptoms of depression and distress.

Henderson (1983) included 13 hospitalized adolescents diagnosed with adjustment reaction. The author aimed to evaluate the influence of 18 one-hour MT on one's mood and emotion in music awareness, one's self-esteem, and group cohesion. To obtain the study data, the participants were asked to use adjectives to describe the emotional nature of musical pieces (mood and emotions in music); then, the Coopersmith Self-Esteem Inventory was used to assess one's self-esteem; finally, group cohesion was estimated through the number of pronouns expressing group feelings ("we, our"), sociograms, and other qualitative data. The intervention group received a receptive approach of MT that included a group discussion about mood and feelings associated with music, analyzing the participants' body language, as well as writing compositions and drawing while music was played in the background. The control group received occupational therapy, recreation therapy, or free time. Although no changes in self-esteem and group cohesion were observed in the intervention group before and after MT, there was an improvement in terms of intergroup differences. These results were also confirmed by the qualitative data collected during the study: body language went from closed to open, the number of adjectives used to describe the music presented during therapy increased, and the number of pronouns expressing group feelings ("we, our”, which indirectly point to group relationships) was greater.

Sharma and Jagdev (2012) aimed to facilitate change through music as therapy for academically stressed children, with particular emphasis on self-esteem. The study was designed to assess the impact of music as therapy in enhancing self-esteem. The authors assumed that MT can refer to the cognitive faculties of a human mind. The authors included 60 adolescents with low self-esteem and high academic stress who underwent receptive MT (the flute version of the raga) for half an hour a day across a period of 15 days. The results revealed that MT enhanced adolescent's self-esteem in subjects from the MT group as compared to the control group. The investigators suggested that self-esteem should be viewed not only as one of the fundamental factors of one's mental health, but also as a protective factor which is conducive to positive social behaviors and prevents harmful social influence.

$\mathrm{Wu}$ (2002) extended the earlier findings on that social perspective to include academic success. The author examined 24 Taiwanese undergraduates who experienced problems due to fear, depression, and low self-esteem. These issues, the author claims, are a threat to one's academic success. According to the author, MT can be a creative method of helping people to achieve both academic and personal successes as well as positive attention, thus building positive self-esteem. Emotional support, self-expression, and control (of lack thereof) can all be conducive to good self-esteem. The MT sessions included active listening to music, singing, and improvisation. The control group received no treatment at all. A qualitative analysis showed that MT resulted in self-growth and manifested itself in greater self-confidence, a decrease in experienced fear and depression symptoms, as well as a greater sense of happiness; however, no changes were observed in self-esteem between the examined groups. Therefore, the obtained results suggest that methods of examining these dependencies should be diversified. 


\section{Case study}

Smeijsters and van den Hurk (1999) carried out a qualitative single-case study of a 56-year-old woman who had problems in finding her personal identity and suffered badly from grief, low self-esteem, and feelings of depression. The goals for the therapy were to help the patient find the true identity, strengthen her self-esteem, express, explore, and contain her feelings. Treatment included musical improvisation on the piano, split drums, and voice. The qualitative analysis showed that MT supported the expression of those parts of the patient's personality that were repressed by earlier life experiences. Furthermore, these sessions helped the patient to establish a new relationship with herself, which then translated into more positive self-esteem and, consequently, into a greater identity integration.

3. Exploratory research

Daykin et al. (2007) continued analyzing the relationship between autobiographical and aesthetic elements. The study once again undertook the problem of personal development associated with aesthetic functions of music and characteristics of musical activities. The researchers assumed that creative expression (an element of MT) can be of restorative value to one's identity. Music was treated as a part of the complementary and alternative medicine (CAM) (noninvasive, focused on psychosocial factors) cancer treatment. This approach was based on the model of health that emphasizes, among other things, a patient's individual responsibility for the healing process. Meetings with therapists make the patients realize that they have a unique ability to influence their health and disease, body and mind. Researchers treat "musicality" as a form of personal capital, which is a predictor of personal involvement in therapy and its success. The authors also called for diversifying identity issues; identity should be a basis for studies on how CAM affects human health. They referred to the concept of creative identity, distinguishing it from creative activity. Patients can experience psychological states that make them realize that they are different from other human beings, that they are special and unique. After analyzing structured interviews with 23 patients diagnosed with cancer, the researchers found a wide range of psychological states related to music-making: joy, power, freedom, fascination, love, community, regret, loss, and isolation. The patients' reaction to music was to a large extent influenced by their identity perspectives and their autobiographical issues. To realize one's talent and musical skills was equivalent to genuine musicality during a session. On the other hand, defining oneself as "not being musical" became a barrier in experiencing fulfillment in MT. Musical identity, defined in the context of either latent or overt musical knowledge or skills, turned out to mediate the effectiveness of MT. Then, creative and innovative personalizing of a therapist's actions can be seen as a factor that facilitates the healing process. The possibility of choosing, the language of hope and expectations that go with it, gave the patients a chance to develop the creative aspects of their identities. This way, MT counteracts the limitations, restrictions, isolation, and powerlessness, and helps a patient to infuse the chaotic disease-related experiences with meaning.

Pavlicevic, O'Neil, Powell, Jones, and Sampathianaki (2014) were interested to evaluate what are the psychosocial needs of young adults with severe learning disabilities and how music-centered therapy responds to these needs. Within the Nordoff Robbins approach, music becomes infused with a very personal/individual factor, characteristic of each patient. Through improvising together, music-related experiences become common, and music itself initiates and fosters the process of self-realization and building self-confidence. This method is adequate for people with communication problems or difficulties in verbal speech. Moreover, this approach is defined as a relational process - in this case, between a patient, a therapist, and a group observed by parents and a team of specialists. The authors noted that spontaneity and flexibility typical of musical activities were in sharp contrast to the failures the participants experienced in their environments of origin. Parents and a team of specialists agreed that the most important result of the MT activities were the long-term developmental changes within one's identity aspects. Wellplanned therapy sessions allow the clients to experience deeply their intrapersonal issues (for example, through making something valuable, through feelings of success and agency), as well as interpersonal ones (growing self-esteem is seen not only as a result of experiencing oneself, but also of positive social and communal experiences). Musical entertainment fosters social relationships, feelings of trust, acceptance, equality, belonging, and group affinity; it encourages self-confidence and involves a growing sense of selfworth and dignity. Also, making music together is an opportunity to get to know other young people and to realize one's abilities to create friendships, thus preventing a sense of loneliness. The authors proposed to go beyond the typical (linear) understanding of how psychological changes occur. Strong emphasis was put on the issues of communion and experiencing social bonds, because it is through communion that patients with severe learning disabilities (SLDs) can build their individual/identity resources.

4. Theoretical papers

The topic of MT, as described here, suggesting strong ties between music and one's personal matters, renders MT more than just a useful healing tool. The symbolism that accompanies music can also make it a valuable source of knowledge about a patient. A description and explanation of music as a medium of understanding and transforming a per-
Identity and self-esteem in the context of music and music therapy 
son can be found in Dorit Amir's (2012) method of musical presentation (MP) (the article not only provides an overview of MP, but also presents a sort of case study - the MP for Daniella, an MT student). The author assumed that people use music as a way of "filming themselves". Music is often associated with important events and stages of one's development and memories of these events also contain that musical context. Musical presentation is a psychological tool to discover and reconstruct a person's musical identity - and to reconstruct the person itself, too. Many techniques are included in musical presentation, but all of them aim to reflect different aspects of the Self. They are built of structural elements such as musical communication, reception of music, and social relationships. Various elements, such as when a therapy member chooses and presents different kinds, types, and genres (chamber music, concertos, symphonies, music ensembles), content and character of music, or even a musician's sex, all come together in the perspective of a listener's subjective experiences (musical taste), and at the same time leading to understanding deeper aspects of psychological functioning. Thanks to musical presentation, participants not only get to know themselves better (increasing the clients' self-awareness) and get to know each other better, but also feel the power and significance of music as a tool of communication and expression. This can reflect both a client's intra- and interpersonal world, and so it can become a map of his or her inner self. The process of preparing this information, sharing it, and obtaining feedback from other therapy members (Which musical compositions do I find most important to me and why? What memories of events, people, and images do certain musical compositions bring to my mind?), processing and integrating one's experiences is in fact the process of composing the history of one's life. Musical presentation is a safe tool, as a therapy member is totally in control of what to share with the group and how to do it. On the other hand, a therapist can get to know and understand some of the deeper aspects of a patient's Self (important life events, unresolved life problems), which would otherwise remain unavailable.

Identity issues and identity integration problems in dissociative identity disorder (DID) clients were undertaken by Gleadhill and Ferris (2010). They presented a theoretical MT framework for working with people with DID. According to the American Psychiatric Association the DID is a debilitating disorder due to severe ongoing neglect or abuse, characterized by the presence of two or more identities that frequently control the individual's behavior. The authors assumed that incorporating music as part of treatment for these individuals may be a remedy for dissociative identity and a lack of self-cohesion. Music therapists, by paying attention to a client's needs and by proposing certain actions (songwriting, musical improvisations, and, after that, analyzing the compositions, either listened to or sung by the client) can help individuals to attain and maintain a sense of control. Ensuring safety and stability, reducing disease-related symptoms, and working on traumatic memories can lead to internal identity integration as well as trauma and dissociation rehabilitation. The authors recognized the process of writing (or mimicking) songs during group therapy sessions as one of the most effective interventions which tackle these issues. The cognitive process of creating a song (and the accompanying process of writing it down) based on one's personal experiences provides a client with a powerful sense of accomplishment and pride, and can lead to boosting one's self-esteem and internal integrity.

\section{DISCUSSION}

Recent years have seen the emergence of some psychological theories which hold that musical organization becomes a model for creating the concept of Self (cf. polyphonic Self and dialogical Self, Lecourt, 1993; Hermans, 1999). These theories were the starting point for this article. An example of how elements of MT are included in self-description is the issue of musical identity explored in this text.

Even everyday observations, yet alone theoretical analysis (e.g., Hargreaves \& North, 1999; Kantor-Martynuska, 2015), are enough to show that the list of beneficial consequences of making use of music is a long one. Music helps us to relax, improves our mood, relieves tension, teaches us aesthetic sensitivity, and boosts our optimism. Directly and indirectly, music helps people to cope with stress. For example, owing to creative forms of music-making an individual will sooner believe in one's own strengths, self-efficacy, will take on challenges and control over the situation - all that will in turn translate into higher self-esteem. This way, perhaps, a person will make better use of social support; music, after all, can prepare listeners for specific events of social nature (cf. Kantor-Martynuska, 2015).

Many of these effects of being in contact with music can also be seen in the process of MT. As indicated in this review, when MT is used these effects become certain rules - they are not accidental or random; quite the contrary, they appear in a predictable and often statistically regular pattern. The qualitative analysis of the literature indicated that MT increases social interaction, improves interpersonal communication, allows choice and control, provides a release for emotions, builds a healthy sense of self, and increases self-awareness. These observations lead us to a more general conclusion: MT might be a path to social and individual growth. This is in keeping with 
the article's main assumption that music has always been a way to express one's identity, both individual and collective (Roe, 1999). Aldridge (1996) suggests that music is a suitable metaphor for identity. In view of the overarching objective of MT, which is to increase a patient's/client's life quality (cf. Boldt, 1996; Kamioka et al., 2014) referring music to one's Self in the process of the MT activities allows to preserve the integrity of one's behaviors, thoughts, and feelings, which is a fundamental strategy of a mentally healthy man's functioning. On the other hand, testing many forms of one's identity within diverse musical experiences (e.g., plays, games, spontaneous creativity) can further its development. Each of these objectives is at the heart of therapeutic interventions carried out or described in this article. When people with disabilities are recruited for such interventions, they become part of the process of composing and performing music (often professionally), so that they can acquire the identities of fully fledged musicians (musical identities). The participants have an opportunity to believe in their abilities anew and to start to separate the areas of their lives where they experience difficulties from those where they are successful. One of the effects of MT, namely a sense of agency (which is considered valuable for both the client and those around them), is a way to provide one's damaged Self with healthful aspects of personality, thus improving one's self-esteem and providing the strength needed to take on new challenges. These empirical discoveries are important because many mental disorders can affect how people see themselves and how their contact with their social environment is formed. Frustration, anger, or a sense of loneliness can very often lead to changes in one's Self and identity. Magee (2002) suggests that MT can move one's "disabled self-concept" to a more "able self-concept”.

In conclusion, the MT actions presented here (often in their improvisational form) are found to be effective in promoting positive identity aspects while soothing a patient's difficult emotional experiences. Thanks to its own structure, music is able to bring structure into one's personal experiences, and due to revitalizing and stimulating one's self-knowledge it prevents the loss of identity.

The included articles not only describe the issue of changing deep aspects of Self, but also show the possibilities of expressing them in different MT-related activities. The studies on musical identity explore the significance of music as an attribute allowing one to express oneself, one's substance which is a base for the self-presentation mechanism (DeNora, 1999). At the same time, researchers try to answer why it is through music that people seek self-knowledge; how this happens; and what the importance of this is, both for the quality of one's life and social functioning (Rentfrow \& Gosling, 2006). Therefore, musi- cal activities are not parallel to everyday life experiences; rather, they are one of its dimensions, layers, and aspects. Once they have been recognized and properly explored, we can better understand how different identity policies function within it. There are, however, many areas of human psychological functioning where individuals are unable to fully express themselves. As shown in the review, self-expression can be hindered by, for example, various forms of exclusion or isolation, emotional factors, or diseases that over the years affect one's physical and mental health. Also, music is used a therapeutic and helping tool when a patient's verbal communication is - for any reason - hampered. Expressing one's needs and experiences in words can be difficult for people of all ages and with diseases of either organic or psychological nature. Difficulties in verbal communication are typical not only of individuals with pervasive developmental disorders, but also those whose language competence has declined as a result of neurodegenerative disorders. Verbal expression can also pose problems for individuals who, as a result of psychological crises, find it difficult to access their internal world of experiences and express what they feel. The therapeutic methods we proposed, such as musical presentation, stem from the assumption that music is like a language and that a therapist is interested in designation of meanings (which are evoked by a musical piece but refer to the world beyond it). By means of the right techniques, a therapist can gain information about a client's musical identity. The next therapy stages aim to restore the disturbed balance in a patient's mental representations system, i.e. the abovementioned processes involving identity formation and personality integration (cf. Greenberg, 1970).

As we ponder over the relationship between MT and the mechanisms concerning Self, the following question arises: what is the nature of this relationship and its importance to health-related issues, MT included? It should be noted that the above considerations are only explorative; it is not possible to directly compare results coming from different countries or even cultures, people of various ages, heterogeneous samples and diagnoses, different approaches to MT, various criteria for group selection and heterogeneous outcome measure. Nonetheless, these studies are seen as a significant starting point for future analyses. The consequence of creating possible (music) selves is changes in the level of self-esteem (cf. Oleś, 2005). But it may seem that participants are making a compensation mechanism and mentally escape from reality (it is not a permanent change in their musical identity and self-esteem). However, addressing this problem requires further, broad, longitudinal exploration. Furthermore, this review concentrates on self-concept involvement and consequences for identity and self-esteem (not for perception of relation with others). Adopting a rela-
Identity and self-esteem in the context of music and music therapy 
tional perspective of musical identity and integrating it with mechanisms of self-extension may enrich future studies.

\section{IMPLICATIONS}

The nature of musical activities shapes one's behaviors and the course of internal psychological processes as well as serving as an expression of one's interior. When we consider the first aspect, it appears that self-esteem (understood as a set of beliefs and opinions about oneself) is an important factor mediating the relationship between musical activity and one's behavior. Evaluative opinions not only play a major role in intrapsychic integration and exploring one's musical identity, but can also influence how effectively one controls one's behaviors. Self-esteem is responsible for setting goals and any potential critique of one's plans and ideas. It allows an individual to make comparisons between one's beliefs about oneself and objective requirements one has to confront. This is how treatments aiming to create more objective self-esteem (positive but not inflated) can become a way to effectively go through identity crises, providing an opportunity for unrestrained identity development.

Being aware of the strong connection between music and its expressive function for one's identity allows a therapist to adjust the therapeutic and educational activities to various individual characteristics - and one should remember that individuation of teaching is of paramount importance. Therapy participants, regardless of their age, social origin, skills, and knowledge, have different ways of participating in musical activities. What are commonly considered ordinary, or even trivial, ways of using music can actually turn out to be extremely personal. The knowledge inferred from analyzing them can lead to better understanding of the participants, which is necessary if the treatment is to be effectively conducted treatment: It must go with one's internal tendencies, not against them. Here we also wish to remind our readers that MT is more effective when the music used in it has been specifically tailored to one's individual needs rather than imposed by a therapist in an authoritative and directive manner.

\section{REFERENCES}

Aldridge, D. (1996). Music therapy research and practice in medicine: From out of the silence. London: Jessica Kingsley.

Aldridge, D., Schmid, W., Kaeder, M., Schmidt, C., \& Ostermann, T. (2005). Functionality or aesthetics? A pilot study of music therapy in the treatment of multiple sclerosis patients. Complementary Therapies in Medicine, 13, 25-33.
Amir, D. (2012). "My music is me": Musical presentation as a way of forming and sharing identity in music therapy group. Nordic Journal of Music Therapy, 21, 176-193.

Boldt, M. M. (1996). The effects of music therapy on motivation, psychological well-being, physical comfort and exercise endurance of bone marrow transplant patients. Journal of Music Therapy, 33, 164-188.

Bruhn, H. (2002). Musical development of elderly people. Psychomusicology, 18, 59-75.

Cattell, R., \& Anderson, J. (1953). The I.P.A.T. Music Preference Test of Personality. Champaign, IL: Institute for Personality and Ability Testing.

Chen, X. J., Hannibal, N., \& Gold, Ch. (2016). Randomized trial of group music therapy with Chinese prisoners: Impact on anxiety, depression, and self-esteem. International Journal of Offender Therapy and Comparative Criminology, 60, 10641081. doi: $10.1177 / 0306624 X 15572795$

Clendenon-Wallen, J. (1991). The use of music therapy to influence the self-confidence and self-esteem of adolescents who are sexually abused. Music Therapy Perspectives, 9, 73-81. doi: 10.1093/mtp/9.1.73

Cook, N. (2000). Music: A very short introduction. Oxford: Oxford University Press.

Daykin, N., McClean, S., \& Bunt, L. (2007). Creativity, identity and healing: Participants' accounts of music therapy in cancer care. Health: An Interdisciplinary Journal for the Social Study of Health, Illness and Medicine, 11, 349-370.

DeNora, T. (1999). Music as technology of Self. Poetics, 27, 31-56.

Fubini, E. (1991). History of music aesthetics. Palgrave Macmillan.

Galińska, E. (2005). Muzykoterapia [Music therapy]. In L. Grzesiuk (ed.), Psychoterapia. Teoria. Podręcznik Akademicki. Tom 1 (Psychotherapy. Theory. Vol. 1) (pp. 531-542). Warszawa: Wydawnictwo Psychologii i Kultury Eneteia.

Gleadhill, L., \& Ferris, K. (2010). A theoretical music therapy framework for working with people with dissociative identity disorder. Australian Journal of Music Therapy, 21, 42-55.

Greenberg, M. (1970). Musical achievement and self-concept. Journal of Research in Music Education, 18, 57-64.

Grocke, D., Bloch, S., Castle, D., Thompson, G., Newton, R., Stewart, S., \& Gold, C. (2014). Group music therapy for severe mental illness: A randomized embedded-experimental mixed methods study. Acta Psychiatrica Scandinavica, 130, 144-153. doi: 10.1111/acps. 12224

Haines, J. H. (1989). The effects of music therapy on the self-esteem of emotionally-disturbed adolescents. Music Therapy, 8, 78-91.

Hanser, S. B., \& Thompson, L. W. (1994). Effects of music therapy strategy on depressed older adults. Journal of Gerontoloqy, 49, 265-269. 
Hargreaves, D. J. (1986). The developmental psychology of music. Cambridge: Cambridge University Press.

Hargreaves, D. J., Miell, D., \& MacDonald, R. A. R. (2002). What are musical identities, and why are they important? In R. A. R. MacDonald, D. Hargreaves, \& D. Miell (eds.), Musical identities (pp. 1-20). New York: Oxford University Press.

Hargreaves, D. J., \& North, A. C. (1999). The functions of music in everyday life: Redefining the social in music psychology. Psychology of Music, 27, 71-83. doi: 10.1177/0305735699271007

Henderson, S. (1983). Effects of a music therapy program upon awareness of mood in music, group cohesion, and self-esteem among hospitalized adolescent patients. Music Therapy, 20, 14-20.

Hermans, H. J. M. (1999). The polyphony of the mind: A multivoiced and dialogical self. In J. Rowan \& M. Cooper (eds.), The plural self. Multiplicity in everyday life (pp. 107-131). London: Sage Publications.

Kamioka, H., Tsutani, K., Yamada, M., Park, H., Okuizumi, H., Tsuruoka, K., Honda, T., Okada, S., Park, S. J., Kitayuguchi, J., Abe, T., Handa, S., Oshio, T., \& Mutoh, Y. (2014). Effectiveness of music therapy: A summary of systematic reviews based on randomized controlled trials of music interventions. Patient Preference and Adherence, 8 , 727-754. doi: 10.2147/PPA.S61340

Kantor-Martynuska, J. (2015). Emotional responses to music and their musical, individual, and situational factors: An integrative approach. Psychological Studies, 53, 30-45. doi: 10.2478/V10167-0100118-7

Kopacz, M. (2005). Personality and music preferences: The influence of personality traits on preferences regarding musical elements. Journal of $\mathrm{Mu}$ sic Therapy, 3, 216-239.

Kuhl, J. (2000). A Functional-design approach to motivation and self-regulation: The dynamics of personality systems interactions. In M. Boekaerts, P. R. Pintrich, \& M. Zidner (eds.), Handbook of self-regulation (pp. 105-134). San Diego: Academic Press.

Larson, R. (1995). Secrets in the bedroom: Adolescents' private use of media. Journal of Youth and Adolescence, 24, 535-550. doi: 10.1007/BF01537055

Lawendowski, R. (2009). Osobowościowe uwarunkowania preferencji muzycznych w zależności od wieku [Personality determinants of music preferences in depending of age]. Kraków: Impuls.

Lecourt, E. (1993). L'expérience musicale. Résonances psychanalytiques [The musical experience. Psychoanalytic resonances]. Paris: l'Harmattan.

Lull, J. (1987). Listeners' communicative properties of music. In J. Lull (ed.), Popular music and communication (pp. 140-174). London: Sage Publications.

MacDonald, R. A. R., \& Miell, D. J. (2002). Music for individuals with special needs: A catalyst for de- velopments in identity, communication, and musical ability. In R. A. R. MacDonald, D. J. Hargreaves \& D. Miell (eds.), Musical Identities (pp. 163-178). Oxford: Oxford University Press.

Magee, W. (2002). Identity in clinic music therapy: Shifting self-constructs through tile therapeutic process. In R. A. R. MacDonald, D. J. Hargreaves, \& D. Miell (eds.), Musical Identities (pp. 179-197). Oxford: Oxford University Press.

North, A. C., \& Hargreaves, D. J. (1999). Music and adolescent identity. Music Education Research, 1, 75-92.

Oleś, P. K. (2005). Wprowadzenie do psychologii osobowości [An introduction to personality psychology]. Warszawa: Wydawnictwo Naukowe Scholar.

Pavlicevic, M., O’Neil, N., Powell, H., Jones, O., \& Sampathianaki, E. (2014). Making music, making friends: Long-term music therapy with young adults with severe learning disabilities. Journal of Intellectual Disability Research, 18, 5-19. doi: 10.1177/1744629513511354

Pyszczynski, T., Greenberg, J., \& Solomon, S. (1999). A dual-process model of defense against conscious and unconscious death-related thoughts: An extension of terror management theory. Psychological Review, 106, 835-845.

Rentfrow, P., \& Gosling, S. (2006). Message in a Ballad: The role of music preferences in interpersonal perception. Psychological Science, 17, 236-242. doi: 10.1111/j.1467-9280.2006.01691.x

Roe, K. (1999). Music and identity among European youth. Soundscape, 2, 1-15.

Rorke, M. A. (1996). Music and the wounded of World War II. Journal of Music Therapy, 33, 189-207. doi: 10.1093/jmt/33.3.189

Schäfer, T., Sedlmeier, P., Städtler, C., \& Huron, D. (2013). The psychological functions of music listening. Frontiers in Psychology, 4, 511. doi: 10.3389/ fpsyg.2013.00511

Sharma, M., \& Jagdev, T. (2012). Use of music therapy for enhancing self-esteem among academically stressed adolescents. Pakistan Journal of Psychological Research, 27, 53-64.

Sloboda, J. (2005). Wyzwania i możliwości psychologii muzyki [Challenges and opportunities of psychology of music]. Warszawa: Wydawnictwo Akademii Muzycznej im. Fryderyka Chopina.

Smeijsters, H., \& van den Hurk, J. (1999). Music therapy helping to work through a grief and finding a personal identity. Journal of Music Therapy, 36, 222-252.

Wu, S. M. (2002). Effects of music therapy on anxiety, depression and self-esteem of undergraduates. Psychologia, 45, 104-114. doi: 10.2117/psysoc. 2002.104
Identity and self-esteem in the context of music and music therapy 